\title{
PERANCANGAN MEDIA KOMUNIKASI BERBASIS WEB UNTUK PEMBELAJARAN
}

\author{
Widyo Nugroho dan Fikri Saleh
}

Universitas Gunadarma, Jl. Margonda Raya, PondokCina, Depok, 16424, Indonesia

E-mail: widyo@staff.gunadarma.ac.id

\begin{abstract}
Abstrak
Pesatnya perkembangan ilmu pengetahuan dan teknologi telah membawa dampak kepada pendidikan, tidak terkecuali di Indonesia. Program pendidikan yang bersifat konvensional sukar dipertahankan seutuhnya, karena tersedianya media dan informasi baru yang semakin banyak dan bervariasi. Salah satu media yang perkembangannya semakin melesat adalah penggunaan komputer. Penggunaan komputer sebagai sarana pendidikan dimungkinkan karena banyak potensi yang dapat dimanfaatkan dari komputer tersebut. Penelitian ini mencoba melihat efektifitas dan efisiensi pembelajaran dengan merancang media komunikasi berbasis web. Situs pembelajaran Universitas telah diujicobakan terhadap tiga puluh mahasiswa. Sebanyak $96 \%$ menyatakan program ini sangat menarik dan sangat membantu dalam kegiatan pembelajaran. Selain itu $90 \%$ menyatakan program ini dapat mengatasi kebosanan terhadap perkuliahan di kelas dalam bentuk metode ceramah.
\end{abstract}

Kata Kunci: media komunukasi berbasis web, web, komunikasi

\begin{abstract}
The rapid development of science and technology has affected education, including in Indonesia. Conventional education programs are difficult to be maintained completely, because the availability of new information media is becoming increasingly numerous and varied. One more shot of media development is the use of computers. The use of computers as a means of education is possible because a lot of potential that can be used from that computer. This study tries to see the effectiveness and efficiency of learning by designing a web-based communications media. The e-learning site has been tested to thirty students. As many as $96 \%$ said the program is very interesting and very helpful in learning activities. In addition $90 \%$ stated that this program can overcome the boredom of lectures in the classroom in the form of the lecture method.
\end{abstract}

Keywords: communication media based on web, web, communication

\section{Pendahuluan}

World Wide Web atau lebih dikenal dengan kata web, adalah icon paling menonjol dalam internet, aplikasi ini dinamis dan paling banyak dimanfaatkan oleh manusia. Konsep awal dari web adalah penggunaan hypertext (dokumendokumen dalam bentuk elektronik yang saling dikaitkan dengan cara tertentu), tetapi seiring berkembangnya teknologi, hypertext berubah menjadi www. Bukan sekedar mengirim text, hypertext juga mampu menyimpan gambar, suara, maupun video, dan bahkan mulai berkembang ke arah multimedia.

Istilah media yang merupakan bentuk jamak dari medium secara harfiah berarti perantara atau pengantar. AECT [1] mengartikan media sebagai segala bentuk dan saluran untuk proses transmisi informasi. Media dapat dikatakan juga sebagai teknologi untuk menyajikan, merekam, membagi dan mendistribusikan simbol dengan melalui rangsangan indera tertentu, disertai penstrukturan informasi.

Kata pembelajaran digunakan untuk menunjukkan usaha pendidikan yang dilaksanakan secara sengaja dengan tujuan yang telah ditetapkan terlebih dahulu, sebelum proses dilaksanakan, serta yang pelaksanaannya terkendali. Dengan perkembangan teknologi informasi dan komunikasi saat ini, pembelajaran mau tidak mau harus terintegrasi dengan web. Hal ini dilakukan untuk mengembangkan kemampuan berfikir tingkat tinggi siswa, disamping itu pengintegrasian ini akan mengembangkan keterampilan siswa dalam bidang teknologi informasi dan komunikasi (ICT literacy).

Miarso [2] mengemukakan bahwa perkembangan teknologi informasi dan komunikasi (TIK) telah memberikan berbagai kemungkinan untuk peningkatan mutu pendidikan, yaitu antara lain untuk: (1) peningkatan akses untuk memperoleh informasi 
dari mana saja, siapa saja, kapan saja dan apa saja, (2) peningkatan efektivitas komunikasi dengan berbagai bentuk rangsangan indera, (3) peningkatan relevansi dengan kebutuhan yang semakin banyak dan beragam, (4) penyesuaian dengan kondisi lingkungan yang berubah, dan (5) peningkatan efisiensi dengan menghemat waktu, tenaga, dan biaya.

Kata media berasal dari bahasa latin dan merupakan bentuk jamak dari kata medium yang secara harfiah berarti perantara atau pengantar. Association for Educational Communication and Technology (AECT), yaitu suatu asosiasi yang bergerak dalam bidang komunikasi pembelajaran yang mendefinisikan media sebagai segala bentuk yang digunakan untuk menyalurkan informasi.

Pengertian media yang diberikan AECT ini adalah pengertian media yang sangat umum, sebab kata semua bentuk yang terdapat dalam pengertian tersebut memberi makna bahwa yang disebut media tidak terbatas pada jenis media tertentu. Jadi apapun bentuknya bila dapat digunakan untuk menyalurkan informasi atau pesan dapat disebut sebagai media.

Dari beberapa pengertian media yang diuraikan di atas, dapat dilihat adanya persamaan antara pengertian yang satu dengan lainnya,terutama pada ruang lingkup pengertian media, serta fungsi dari media tersebut. Semua pengertian media mengacu pada pengertian media secara umum, sedangkan fungsinya menyalurkan informasi atau pesan dari sumber ke penerima.

Dalam proses belajar mengajar, pengajar mengembangkan kiat tertentu agar materi yang disampaikan dapat diterima. Salah satu cara yang digunakan adalah menggunakan media sebagai alat bantu dalam proses belajar mengajar. Media dapat menyajikan pesan serta merangsang siswa untuk belajar. Seiring dengan perkembangannya, teknologi informasi dan komunikasi juga membawa dampak pada wujud dan ragam media yang digunakan, salah satunya adalah media komunikasi berbasis web.

Chaeruman dalam Jurnal Teknodik [3] mengemukakan bahwa untuk mendorong kesiapan SDM di era global melalui pendidikan di sekolah, pengitegrasian TIK dalam proses pembelajaran perlu dilakukan untuk: (1) mengembangkan kemampuan berfikir tingkat tinggi siswa, (2) mengembangkan keterampilan dalam bidang teknologi informasi dan komunikasi (ICT literacy) itu sendiri, dan (3) untuk meningkatkan efektifitas, efisiensi, dan daya tarik proses pembelajaran.

Teknologi Informasi dan Komunikasi (TIK) adalah bagian dari ilmu pengetahuan dan teknologi (IPTEK) yang secara umum merupakan teknologi yang berhubungan dengan pengambilan, pengumpulan, pengolahan, penyimpanan, penyebaran dan penyajian informasi [4]. Dalam definisi itu cakupan TIK meliputi semua perangkat keras, lunak, kandungan isi, dan infrastruktur komputer dan telekomunikasi. TIK dapat terdiri dari komputer (PC), printer, LCD projector, internet, intranet, televisi, radio, handphone, dan lainnya. Banyak orang mengartikan TIK dengan komputer atau segala sesuatu tentang komputer bahkan merupakan urusan guru komputer saja. Hal yang perlu diklarifikasi menurut peneliti berdasarkan definisi TIK tersebut adalah bahwa komputer merupakan bagian dari TIK yang dapat dimanfaatkan untuk pembelajaran.

Penelitian ini mencoba mengembangkan media komunikasi berbasis web sebagai salah satu upaya mengintegrasikan teknologi informasi dan komunikasi dalam proses pembelajaran di Universitas Gunadarma.

\section{Metodologi}

Penelitian ini terdiri dari tiga tahap. Di mana langkah-langkah penelitian mengacu pada siklus penelitian dan pengembangan Borg dan Gall [5], dengan uraian penjelasan yang telah disesuaikan dengan tujuan penelitian, seperti yang digambarkan pada tabel I.

Pengembangan web tidak mempunyai suatu metodologi khusus dalam prakteknya, biasanya suatu pengembangan web lazimnya mengikuti metodologi pengembangan perangkat lunak yang sudah ada sebelumnya. Proses pengembangan yang umum digunakan untuk mengembangkan suatu web biasanya bertolak dari proses pengembangan perangkat lunak konvensional atau biasa dikenal dengan siklus hidup perangkat lunak (SWDLC) yang mempunyai berbagai macam model pengembangan yang dapat diterapkan sesuai dengan perangkat lunak yang akan dikembangkan.

\section{Hasil dan Pembahasan}

Pembelajaran elektronik berbasis web ini dibuat dengan ide untuk memberikan siswa suatu mekanisme pembelajaran elektronik, di mana siswa dapat mempelajari suatu mata kuliah sesuai dengan kemampuannya sendiri dengan menggunakan berbagai macam media, tulisan, audio, ataupun video. Situs pembelajaran elektronik ini juga dibuat untuk mempermudah proses pemahaman mata kuliah, sehingga membantu meringankan beban pengajar dalam menyampaikan materi perkuliahan, namun bukan untuk menggantikan peran pengajar dalam penyampaian materi. 
TABEL I

TAHAPAN PENGEMBANGAN MODEL

\begin{tabular}{|c|c|c|}
\hline Tahap & Langkah & Aktifitas \\
\hline $\begin{array}{l}\text { PraPengembang } \\
\text { an Model }\end{array}$ & 1 & $\begin{array}{l}\text { - Penelitian dan } \\
\text { pengumpulan data awal } \\
\circ \text { Penelitian pendahuluan } \\
\circ \text { Penyusunan hasil } \\
\text { penelitian } \\
\text { O Analisa kebutuhan } \\
\circ \text { Perancangan model }\end{array}$ \\
\hline $\begin{array}{l}\text { Pengembangan } \\
\text { Model }\end{array}$ & 2 & 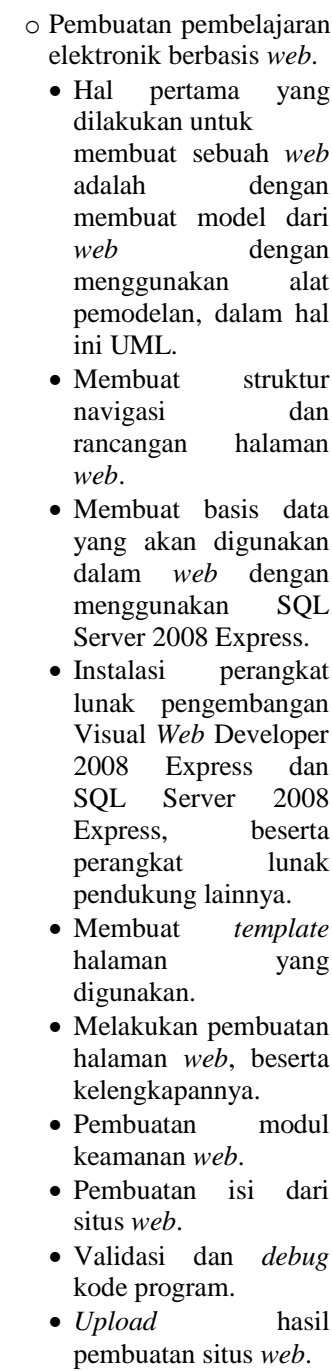 \\
\hline Evaluasi Model & 3 & $\begin{array}{ll}\circ & \text { Uji coba awal } \\
\circ & \text { Kajian dengan ahli } \\
\text { materi, ahli media, dan } \\
\text { ahli teknologi informasi } \\
\text { dan komunikasi. } \\
\circ \text { Perbaikan }\end{array}$ \\
\hline $\begin{array}{l}\text { Penerapan } \\
\text { Model }\end{array}$ & 4 & $\begin{array}{lr}\text { O Uji Coba Lapangan } \\
\text { Uji coba pada beberapa } \\
\text { responden } & \text { mahasiswa } \\
\text { yang ada } & \text { secara acak } \\
\text { pada } & \text { Universitas } \\
\text { Gunadarma } & \end{array}$ \\
\hline Revisi Model & 5 & $\begin{array}{l}\text { Perbaikan Operasional } \\
\text { Peyempurnaan } \\
\text { berkelanjutan dari situs } \\
\text { pembelajaran elektronik }\end{array}$ \\
\hline
\end{tabular}

Sebelum suatu situs pembelajaran elektronik dibuat, terlebih dahulu harus dibuat sebuah model. Dalam hal ini yang dibuat adalah model konseptual, dengan menggunakan UML dan diagram paket yang mendefiniskan fungsi apa saja yang nantinya akan diimplementasikan pada situs.

Secara umum dapat dilihat dari gambar 1, situs pembelajaran elektronik berbasis web terdiri dari lima fungsi pendukung lainnya. Fungsi tersebut meliputi manajemen pengguna, pustaka media pembelajaran, pembelajaran multimedia interkaktif, interaksi asinkron, dan interaksi sinkron. Fungsi tersebut merupakan fungsi yang saling terintegrasi dalam situs pembelajaran elektronik.Fungsi manajemen pengguna adalah suatu mekanisme pengendalian yang dimiliki situs untuk memanajemen penggunaan situs. Manajemen pengguna dilakukan dengan mengintegrasikan fasilitas pembuatan akun pengguna serta akses penggunaan situs menggunakan akun pengguna. Fungsi ini diintegrasikan pada situs sebagai pengamanan situs dengan menggunakan authentication berbasis form.

Fungsi berikutnya adalah fungsi pustaka media pembelajaran yang merupakan suatu fungsi untuk melakukan penyimpanan pada modul pembelajaran yang berbentuk dokumen elektronik. Fungsi ini memungkinkan pengguna situs untuk mengunduh modul pembelajaran berbasis dokumen elektronik.

Fungsi pembelajaran multimedia interaktif merupakan fungsi kunci dari situs ini. Pada fungsi ini terdapat sarana pembelajaran berbasis web dengan menggunakan berbagai macam media seperti suara dan video serta aplikasi multimedia interaktif berbasis flash. Dengan adanya multimedia interaktif para pengguna mendapatkan pembelajaran yang lebih intuitif dibanding dengan pembelajaran biasa pada umunya. Hal tersebut dikarenakan aplikasi multimedia interaktif menekankan pada interaksi antara manusia dengan komputer dalam hal ini komputer sebagai alat bantu ajar.

Hasil dari penelitian dengan 30 responden yang seluruhnya merupakan mahasiswa Universitas Gunadarma dipresentasikan dengan menggunakan analisa deskriptif. Keempat indikator, kualitas dan kompatibilitas situs, kualitas tampilan, penyajian materi, dan interaksi pemakai akan dianalisa terlebih dahulu menggunakan tabel distribusi frekuensi seperti pada tabel II (indikator kualitas dan kompatibilitas). kemudian tabel III untuk indikator kualitas tampilan, tabel IV untuk indikator penyajian materi, dan tabel $\mathrm{V}$ untuk indikator interaksi pemakai.

Pada tabel distribusi frekuensi terlihat 
sebagian besar responden berpendapat bahwa kinerja situs dalam hal kualitas dan kompatibilitas terbilang baik. Pada variabel KK2 (kemudahan akses dalam browser) sebanyak 50\% responden menjawab baik, yang menunjukan situs dapat terakses dengan mudah. Serta pada variabel KK12 (penyajian informasi) situs memperoleh hasil yang baik, dengan $70 \%$ responden menjawab baik pada variabel tersebut. Pada variabel KK10 (akses web dengan menggunakan Opera) $73.3 \%$ berpendapat netral, hal ini dikarenakan browser Opera mempunyai pengguna yang tidak sampai $3 \%$ diseluruh dunia dibandingkan dengan Internet Explorer atau Firefox mempunyai persentase pengguna di atas $40 \%$. Hal itu pula yang mendasari pengujian situs menggunakan browser Firefox dan Internet Explorer. Kesimpulan yang dapat diambil dari hasil analisa indikator kualitas dan kompatibilitas adalah situs web telah mempunyai kualitas yang cukup baik tetapi masih memiliki kekurangan kompatibilitas dengan beberapa browser yang beredar.

Pada tabel distribusi frekuensi indikator kualitas tampilan situs hanya memperoleh hasil yang biasa saja. Pada variabel KT1 (petunjuk penggunaan situs), KT4 (penggunaan animasi), KT6 (kejelasan suara dan narasi), dan KT7 (musik yang digunakan) antara $20.0 \%$ hingga $50 \%$ responden menjawab netral. Di mana hal ini menunjukan segi tampilan situs masih membutuhkan perbaikan. Pada variabel KT2 (tingkat keterbacaan teks) $66.7 \%$ responden mempunyai persepsi yang cukup baik. Dapat diambil sebuah kesimpulan dari distribusi untuk indikator kualitas dan tampilan. Kesimpulan yang dapat ditarik adalah situs membutuhkan perbaikan dalam hal tampilan pada setiap halamannya dan perbaikan narasi. Hasil dari tabel distribusi frekuensi menunjukkan $43.3 \%$ hingga $56.7 \%$ responden menjawab baik pada setiap variabel dari indikator penyajian materi. Dengan sebagian besar sisa responden $26.7 \%$ hingga $43.3 \%$ menjawab netral, hal ini menunjukkan bahwa kinerja situs dalam hal penyajian materi sudah baik. Variabel dengan kinerja paling baik adalah variabel PM1 (kejelasan tujuan pembelajaran) dan PM2 (kejelasan petunjuk penggunaan modul) sebesar 56.7\%. Dari hasil ini, tidak akan ada perubahan materi pada situs yang akan dibuat dari situs yang telah ada sebelumnya. Namun akan ada penambahan beberapa materi yang belum tersedia. Pada tabel distribusi frekuensi, untuk indikator interaksi pemakai, menunjukkan $30.0 \%$ hingga $60 \%$ responden berpendapat baik dengan sisanya $23.3 \%$ hingga $43.3 \%$ berpendapat netral.

Pada variabel seperti variabel IP3 (urutan tampilan) sebanyak $60 \%$ berpendapat bahwa urutan tampilan sudah dapat disajikan dengan baik. Begitu juga dengan variabel IP4 (menu pilihan) sebanyak $50 \%$ responden berpendapat situs telah memiliki menu pilihan yang dapat berfungsi dengan baik. Kontras pada variabel IP7 (panduan cerdas) sebanyak $43.3 \%$ responden menjawab netral yang berarti situs masih membutuhkan panduan cerdas yang dapat membantu pengguna.

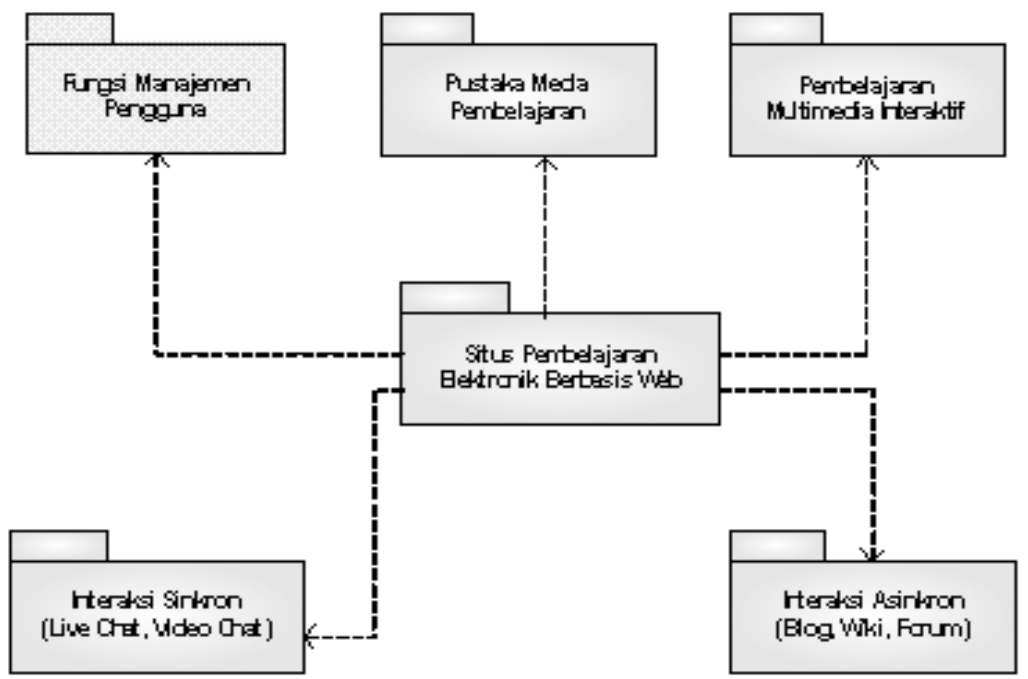

Gambar 1. Model umum dari situs 
104 Journal of Information Systems, Volume 5, Issues 2, October 2009

TABEL II

DISTRIBUSI FREKUENSI INDIKATOR A (KUALITAS DAN KOMPATIBILITAS)

\begin{tabular}{ccccccccccccc}
\hline \hline & \multicolumn{2}{c}{ Tidak baik } & \multicolumn{2}{c}{ Kurang baik } & \multicolumn{2}{c}{ Netral } & \multicolumn{2}{c}{ Baik } & \multicolumn{2}{c}{ Sangat baik } & \multicolumn{2}{c}{ TOTAL } \\
\hline & F & \% Valid & F & $\%$ Valid & F & $\%$ Valid & F & $\%$ Valid & F & $\%$ Valid & F & $\%$ Valid \\
KK1 & 1 & $3.3 \%$ & $\mathbf{1 0}$ & $\mathbf{3 3 . 3 \%}$ & 9 & $30.0 \%$ & 7 & $23.3 \%$ & 3 & $10.0 \%$ & 30 & $100 \%$ \\
KK2 & 1 & $3.3 \%$ & 4 & $13.3 \%$ & 7 & $23.3 \%$ & $\mathbf{1 5}$ & $\mathbf{5 0 . 0 \%}$ & 3 & $10.0 \%$ & 30 & $100 \%$ \\
KK3 & & & 6 & $20.0 \%$ & $\mathbf{1 1}$ & $\mathbf{3 6 . 7 \%}$ & $\mathbf{1 1}$ & $\mathbf{3 6 . 7 \%}$ & 2 & $6.7 \%$ & 30 & $100 \%$ \\
KK4 & 1 & $3.3 \%$ & 3 & $10.0 \%$ & 11 & $36.7 \%$ & $\mathbf{1 2}$ & $\mathbf{4 0 . 0 \%}$ & 3 & $10.0 \%$ & 30 & $100 \%$ \\
KK5 & & & 2 & $6.7 \%$ & 9 & $30.0 \%$ & $\mathbf{1 4}$ & $\mathbf{4 6 . 7 \%}$ & 5 & $16.7 \%$ & 30 & $100 \%$ \\
KK6 & 1 & $3.3 \%$ & 4 & $13.3 \%$ & 8 & $26.7 \%$ & $\mathbf{1 1}$ & $\mathbf{3 6 . 7 \%}$ & 6 & $20.0 \%$ & 30 & $100 \%$ \\
KK7 & & & 3 & $10.0 \%$ & $\mathbf{1 6}$ & $\mathbf{5 3 . 3 \%}$ & 9 & $30.0 \%$ & 2 & $6.7 \%$ & 30 & $100 \%$ \\
KK8 & & & 1 & $3.3 \%$ & 12 & $40.0 \%$ & $\mathbf{1 4}$ & $\mathbf{4 6 . 7 \%}$ & 3 & $10.0 \%$ & 30 & $100 \%$ \\
KK9 & & & 3 & $10.0 \%$ & $\mathbf{2 0}$ & $\mathbf{6 6 . 7 \%}$ & 16 & $20.0 \%$ & 1 & $3.3 \%$ & 40 & $100 \%$ \\
KK10 & 1 & $3.3 \%$ & 2 & $6.7 \%$ & $\mathbf{2 2}$ & $\mathbf{7 3 . 3 \%}$ & 5 & $16.7 \%$ & & & 30 & $100 \%$ \\
KK11 & 1 & $3.3 \%$ & 1 & $3.3 \%$ & $\mathbf{1 4}$ & $\mathbf{4 6 . 7 \%}$ & $\mathbf{1 2}$ & $\mathbf{4 6 . 7 \%}$ & 2 & $6.7 \%$ & 30 & $107 \%$ \\
KK12 & & & 2 & $6.7 \%$ & 5 & $16.7 \%$ & $\mathbf{2 1}$ & $\mathbf{7 0 . 0 \%}$ & 2 & $6.7 \%$ & 30 & $100 \%$ \\
KK13 & & & 2 & $6.7 \%$ & 9 & $30.0 \%$ & $\mathbf{1 7}$ & $\mathbf{5 6 . 7 \%}$ & 2 & $6.7 \%$ & 30 & $100 \%$ \\
KK14 & 1 & $3.3 \%$ & 7 & $23.3 \%$ & $\mathbf{1 7}$ & $\mathbf{5 6 . 7 \%}$ & 5 & $16.7 \%$ & & & 30 & $100 \%$ \\
\hline \hline
\end{tabular}

TABEL III

DITRIBUSI FREKUENSI INDIKATOR B (KUALITAS TAMPILAN)

\begin{tabular}{|c|c|c|c|c|c|c|c|c|c|c|c|c|}
\hline & \multicolumn{2}{|c|}{ Tidak baik } & \multicolumn{2}{|c|}{ Kurang baik } & \multicolumn{2}{|c|}{ Netral } & \multicolumn{2}{|c|}{ Baik } & \multicolumn{2}{|c|}{ Sangat baik } & \multicolumn{2}{|c|}{ TOTAL } \\
\hline & $\mathrm{F}$ & $\%$ Valid & F & $\%$ Valid & $\mathrm{F}$ & $\%$ Valid & $\mathrm{F}$ & $\%$ Valid & $\mathrm{F}$ & $\%$ Valid & $\mathrm{F}$ & $\%$ Valid \\
\hline KT1 & 2 & $6.7 \%$ & 6 & $20.0 \%$ & 11 & $36.7 \%$ & 11 & $36.7 \%$ & & & 30 & $100 \%$ \\
\hline KT2 & 1 & $3.3 \%$ & 2 & $6.7 \%$ & 6 & $20.0 \%$ & 20 & $66.7 \%$ & 1 & $3.3 \%$ & 30 & $100 \%$ \\
\hline KT3 & 2 & $6.7 \%$ & 5 & $16.7 \%$ & 8 & $26.7 \%$ & 12 & $40.0 \%$ & 3 & $10.0 \%$ & 30 & $100 \%$ \\
\hline KT4 & 1 & $3.3 \%$ & 10 & $33.3 \%$ & 11 & $36.7 \%$ & 7 & $23.3 \%$ & 1 & $3.3 \%$ & 30 & $100 \%$ \\
\hline KT5 & 2 & $6.7 \%$ & 7 & $23.3 \%$ & 7 & $23.3 \%$ & 12 & $40.0 \%$ & 2 & $6.7 \%$ & 30 & $100 \%$ \\
\hline KT6 & & & 6 & $20.0 \%$ & 15 & $\mathbf{5 0 . 0 \%}$ & 8 & $26.7 \%$ & 1 & $3.3 \%$ & 30 & $100 \%$ \\
\hline KT7 & 1 & $3.3 \%$ & 5 & $16.7 \%$ & 14 & $46.7 \%$ & 8 & $26.7 \%$ & 2 & $6.7 \%$ & 30 & $100 \%$ \\
\hline
\end{tabular}

TABEL IV

DISTRIBUSI FREKUENSI INDIKATOR C (PENYAJIAN MATERI)

\begin{tabular}{|c|c|c|c|c|c|c|c|c|c|c|c|c|}
\hline & \multicolumn{2}{|c|}{ Tidak baik } & \multicolumn{2}{|c|}{ Kurang baik } & \multicolumn{2}{|c|}{ Netral } & \multicolumn{2}{|c|}{ Baik } & \multicolumn{2}{|c|}{ Sangat baik } & \multicolumn{2}{|c|}{ TOTAL } \\
\hline & $\mathrm{F}$ & $\%$ Valid & $\mathrm{F}$ & $\%$ Valid & $\mathrm{F}$ & $\%$ Valid & $\mathrm{F}$ & $\%$ Valid & $\mathrm{F}$ & $\%$ Valid & $\mathrm{F}$ & $\%$ Valid \\
\hline PM1 & & & 5 & $16.7 \%$ & 8 & $26.7 \%$ & 17 & $56.7 \%$ & & & 30 & $100 \%$ \\
\hline PM2 & 1 & $3.3 \%$ & 5 & $20.0 \%$ & 7 & $43.3 \%$ & 17 & $56.7 \%$ & & & 30 & $123 \%$ \\
\hline PM3 & 1 & $3.3 \%$ & 3 & $10.0 \%$ & 10 & $33, \%$ & 14 & $46.7 \%$ & 2 & $6.7 \%$ & 30 & $100 \%$ \\
\hline PM4 & 1 & $3.3 \%$ & 3 & $10.0 \%$ & 11 & $36.7 \%$ & 15 & $50.0 \%$ & & & 30 & $100 \%$ \\
\hline PM5 & & & 3 & $10.0 \%$ & 10 & $33.3 \%$ & 17 & $56.7 \%$ & & & 30 & $100 \%$ \\
\hline PM6 & & & 3 & $10.0 \%$ & 13 & $43.3 \%$ & 13 & $43.3 \%$ & 1 & $3.3 \%$ & 30 & $100 \%$ \\
\hline PM7 & & & 3 & $10.0 \%$ & 13 & $43.3 \%$ & 13 & $43.3 \%$ & 1 & $3.3 \%$ & 30 & $100 \%$ \\
\hline PM8 & & & & & 11 & $36.7 \%$ & 15 & $\mathbf{5 0 . 0 \%}$ & 4 & $13.3 \%$ & 30 & $100 \%$ \\
\hline
\end{tabular}


TABEL V

DISTRIBUSI FREKUENSI INDIKATOR D (INTERAKSI PEMAKAI)

\begin{tabular}{ccccccccccccc}
\hline \hline & \multicolumn{2}{c}{ Tidak baik } & \multicolumn{2}{c}{ Kurang baik } & \multicolumn{2}{c}{ Netral } & \multicolumn{2}{c}{ Baik } & \multicolumn{2}{c}{ Sangat baik } & \multicolumn{2}{c}{ TOTAL } \\
\hline & F & $\%$ Valid & F & $\%$ Valid & F & $\%$ Valid & F & $\%$ Valid & F & $\%$ Valid & F & $\%$ Valid \\
IP1 & 1 & $3.3 \%$ & 3 & $10.0 \%$ & 10 & $33.3 \%$ & $\mathbf{1 1}$ & $\mathbf{3 6 . 7 \%}$ & 5 & $16.7 \%$ & 30 & $100 \%$ \\
IP2 & & 6 & $20.0 \%$ & 9 & $30.0 \%$ & $\mathbf{1 3}$ & $\mathbf{4 3 . 3 \%}$ & 2 & $6.7 \%$ & 30 & $100 \%$ \\
IP3 & & 3 & $10.0 \%$ & 7 & $23.3 \%$ & $\mathbf{1 8}$ & $\mathbf{6 0 . 0 \%}$ & 2 & $6.7 \%$ & 30 & $100 \%$ \\
IP4 & & 1 & $3.3 \%$ & 12 & $40.0 \%$ & $\mathbf{1 5}$ & $\mathbf{5 0 . 0 \%}$ & 2 & $6.7 \%$ & 30 & $100 \%$ \\
IP5 & & & 4 & $13.3 \%$ & 12 & $40.0 \%$ & $\mathbf{1 2}$ & $\mathbf{4 0 . 0 \%}$ & 2 & $6.7 \%$ & 30 & $100 \%$ \\
IP6 & 1 & $3.3 \%$ & 7 & $23.3 \%$ & $\mathbf{1 0}$ & $\mathbf{3 3 . 3 \%}$ & 9 & $30.0 \%$ & 3 & $10.0 \%$ & 30 & $100 \%$ \\
IP7 & 1 & $3.3 \%$ & 5 & $16.7 \%$ & $\mathbf{1 3}$ & $\mathbf{4 3 . 3 \%}$ & 10 & $33.3 \%$ & 1 & $3.3 \%$ & 30 & $100 \%$ \\
IP8 & & 7 & $23.3 \%$ & 10 & $33.3 \%$ & $\mathbf{1 1}$ & $\mathbf{3 6 . 7 \%}$ & 2 & $6.7 \%$ & 30 & $100 \%$ \\
IP9 & & & 6 & $20.0 \%$ & $\mathbf{1 1}$ & $\mathbf{3 6 . 7 \%}$ & $\mathbf{1 1}$ & $\mathbf{3 6 . 7 \%}$ & 2 & $6.7 \%$ & 30 & $100 \%$ \\
IP10 & & & 5 & $16.7 \%$ & $\mathbf{1 2}$ & $\mathbf{4 0 . 0 \%}$ & $\mathbf{1 2}$ & $\mathbf{4 0 . 0 \%}$ & 1 & $3.3 \%$ & 30 & $100 \%$ \\
IP11 & 1 & $3.3 \%$ & 8 & $26.7 \%$ & 8 & $26.7 \%$ & $\mathbf{1 3}$ & $\mathbf{4 3 . 3 \%}$ & & & 30 & $100 \%$ \\
IP12 & & 8 & $26.7 \%$ & 9 & $30.0 \%$ & 11 & $30.0 \%$ & 2 & $6.7 \%$ & 30 & $93 \%$ \\
\hline \hline
\end{tabular}

\section{Kesimpulan}

Dari hasil analisa deskriptif yang telah dilakukan pada data yang diperoleh dari kuesioner, dapat ditarik suatu kesimpulan yang berkenaan dengan kinerja dari situs. Secara keseluruhan kinerja situs sudah dapat dikatakan telah memberikan kinerja yang diharapkan dan mempunyai fungsi sesuai yang diharapkan. Indikator kualitas, kompatibilitas, serta penyajian materi memberikan kinerja yang baik, tetapi dengan catatan pada indikator kualitas tampilan dan interaksi pemakai.

Indikator kualitas dan kompatibilitas serta penyajian materi menunjukan kinerja yang memuaskan. Hal tersebut dapat dilihat dengan kecenderungan responden berpendapat baik pada beberapa variabel di dalam indikator kualitas dan kompatibilitas serta berpendapat baik pada hampir semua variabel di dalam indikator penyajian materi. Sedangkan pada indikator kualitas tampilan dan interaksi pemakai, situs menunjukkan kinerja yang biasa saja, dengan sebagian besar responden memilih untuk berpendapat netral pada hampir semua variabel yang terdapat pada kedua indikator tersebut.
Dengan hasil tersebut dapat diasumsikan bahwa mahasiswa membutuhkan suatu situs pembelajaran berbasis web dengan tampilan dan interaksi pemakai yang lebih baik.

\section{Referensi}

[1] L.A. Schlosser and M. Simonson, "Distance Education: Definition and Glossary of Terms," Association For Education Communication and Technology, 1977.

[2] Y. Miarso, Menyemai Benih Teknologi Pendidikan, Kencana, Jakarta, 2004.

[3] U.A. Chaeruman, "Mengintegrasikan Teknologi Informasi dan Komunikasi (TIK) ke dalam Proses Pembelajaran; Apa, Mengapa dan Bagaimana?," Jurnal Teknodik, vol. IX, pp. 46-59, 2005.

[4] E. Haryanto, Teknologi Informasi dan Komunikasi; Konsep dan Perkembangannya, DIKNAS,

http://media.diknas.go.id/media/document/5 595.pdf, 2008, retrieved January 16, 2009.

[5] W.R. Borg \& M.D. Gall, Educational Research An Introduction, 4th ed., Longman Inc, New York, 1983. 